\title{
Evaluation of Hypocaloric Diet With Protein Supplementation in Middle-Aged Sarcopenic Obese Women: A Pilot Study
}

\author{
Rosa Sammarco ${ }^{a}$ Maurizio Marra ${ }^{a}$ Maria Luisa Di Guglielmo ${ }^{a}$ \\ Marianna Naccarato ${ }^{a}$ Franco Contaldo ${ }^{a, b} \quad$ Eleonora Poggiogalle ${ }^{c}$ \\ Lorenzo Maria Doninic Fabrizio Pasanisi ${ }^{\mathrm{a}}$ b \\ a Department of Clinical Medicine and Surgery, University Federico II, Naples, Italy; \\ ${ }^{b}$ Interuniversity Centre for Obesity and Eating Disorders (CISRODCA), Federico II University \\ of Naples, Naples, Italy; ' Food Science and Human Nutrition Research Unit, Food Science \\ and Endocrinology Section, Medical Pathophysiology, Experimental Medicine Department, \\ Sapienza University of Rome, Rome, Italy
}

\section{Keywords}

Obesity $\cdot$ Sarcopenia $\cdot$ Body composition $\cdot$ Hypocaloric diet $\cdot$ Protein supplementation

\begin{abstract}
Objective: The aim of this study was to evaluate the efficacy of a nutritional program, which is characterized by a different modulation of proteins, in adult patients with sarcopenic obesity. Methods: We studied 18 obese women aged 41-74 years. Obesity was diagnosed as fat mass $>34.8 \%$ and sarcopenia was defined when lean body mass was $<90 \%$ of the subject's ideal fat free mass. All subjects were randomly assigned to different nutritional interventions: Hypocaloric diet plus placebo (A) and hypocaloric high-protein diet (1.2-1.4 g / kg body weight reference / day) (B). Anthropometric measurements, body composition, resting energy expenditure, handgrip test, Short Physical Performance Battery (SPPB), and SF-36 questionnaire were evaluated at baseline and after 4 months. Results: Weight significantly decreased in both groups. Women with high-protein diet preserved lean body mass compared to low-calorie diet and improved significantly muscle strength; SPPB score did not change in both groups. SF-36 test showed a significant change for general health after 4 months in group B. Conclusions: In our study, sarcopenic obese patients with high-protein diet showed an improvement in muscle strength. Furthermore, dietary protein enrichment may represent a protection from the risk of sarcopenia following a hypocaloric diet.
\end{abstract}

(C) 2017 The Author(s)

Published by S. Karger GmbH, Freiburg

Dr. Maurizio Marra, BSc, PhD

Department of Clinical Medicine and Surgery

Federico II University Medical School

Via Pansini 5, 80131 Naples, Italy

marra@unina.it 


\section{Introduction}

The term sarcopenia, derived from two ancient Greek words (sarcos and penia, i.e.,'flesh' and 'loss'), was used for the first time in 1989 by Rosenberg [1] to describe the loss of muscle mass correlated with aging. Since then, the term sarcopenia defined a syndrome characterized by a progressive and generalized loss of skeletal muscle mass and muscle strength, which is accompanied by a reduction in the quality of life and increased risk of disability and death [2-3]. This definition of sarcopenia has been developed in 2010 by the European Working Group on Sarcopenia in Older People (EWGSOP) that suggests a different classification staging as: 'pre-sarcopenia', 'sarcopenia' and 'severe sarcopenia' [4]. However, the growing elderly population and the increasing incidence of obesity in Western societies require more accurate studies to evaluate the prevalence of sarcopenia in this group and its related risks. Moreover, the prevalence of sarcopenic obesity is rising in obese adults due to an imbalance between lean mass, excess body fat and total body size that appears earlier in life, because of the disproportion between the even conserved lean mass when compared to fat mass and exceeding body weight that lean mass could support [5].

Most of the literature focuses on the obesity/poor muscle mass combination, usually defined as sarcopenic obesity. Sarcopenic obesity was defined for the first time in 1996 by Heber et al. [6] as the combination of reduced fat free mass (FFM) evaluated by bioimpedance analysis (BIA) and fat mass excess, expressed as percent of body weight. In a recent review, criteria adopted by different authors partially overlapped. One of the main obstacles is represented by the definition of sarcopenic obesity and especially whether it should be based only on criteria of body composition or functional criteria should also be taken into account [7].

Changes in body composition typically occur during the aging process: lean body mass tends to decline with age, accompanied by a relative increase of total adipose tissue with fat infiltration of muscles [8]. Moreover, engagement in sedentary activities as well as unhealthy dieting may lead to the development of phenotypic aspects of sarcopenic obesity even in younger subjects [9]. Chronic inflammation induced by obesity is the main factor accounting for additional depletion of muscle mass $[8,10]$. Furthermore, weight cycling is known to exert deleterious effects on body composition being responsible for a greater reduction of lean body mass during the weight loss phase than gain of lean mass when weight is regained [11]. Even though sarcopenic obesity currently represents a serious public health concern, strong evidence supporting effective strategies for management is still limited, and a consensus for its diagnosis as well as treatment is far to be achieved $[5,12]$.

There are only few studies in the literature screening for sarcopenia in obesity and its relationship with protein content of diet and protein supplementation with different study protocols [13-16].

The aim of this study was to evaluate the efficacy of a dietary program, which is characterized by a different modulation of individual nutrients and proteins, on body composition, resting energy expenditure (REE), muscle strength, and quality of life in adult female patients with sarcopenic obesity.

\section{Material and Methods}

We recruited 18 women, aged 41-74 years (mean age $55.0 \pm 9.6$ years) , (weight $103 \pm 12 \mathrm{~kg}$; height 158 $\pm 4 \mathrm{~cm}$; BMI $41 \pm 5 \mathrm{~kg} / \mathrm{m}^{2}$ ), who consecutively underwent clinical evaluations at the Obesity Unit of the Department of Clinical Medicine and Surgery, Federico II University Hospital, in Naples, Italy. All patients satisfied criteria for sarcopenic obesity at entry.

The presence of sarcopenic obesity was considered when the following two conditions were satisfied:

- $\quad$ Fat mass $>34.8 \%$ 
- $\quad$ FFM was considered depleted if it was $<90 \%$ of subject's ideal FFM.

Considering that fat mass in normal-weight subjects corresponds to about $25 \%$ in women [17-18], ideal FFM was calculated in $\mathrm{kg}$ as the sum of: $75 \%$ of ideal body weight, plus $25 \%$ of excess weight, expressed as body weight exceeding a reference body weight with a BMI $=25 \mathrm{~kg} / \mathrm{m}^{2}$ (i.e., ideal $\mathrm{FFM}=0,75 \times$ ideal body weight $+0,25 \times$ excess body weight) [19-20].

At entry, percent fat mass and real FFM / ideal FFM was $53.4 \pm 4.81 \%(\min 44.71 \%, \max 59.43 \%)$ and $0.83 \pm 0.04$ ( $\min 0.75$, max 0.89 ), respectively.

The protocol of the multicenter study was approved by the Ethical Committee of the Azienda Ospedaliera Umberto I, Rome (prot. 166/12). All patients gave written informed consent for participation to the study. The study was carried out according to Helsinky declaration.

At the beginning of the study and after 4 months, we carried out the evaluation of the 18 patients (body composition, functional and quality of life assessments).

Height was measured to the nearest $0.1 \mathrm{~cm}$ with a stadiometer; body weight was measured to the nearest $0.1 \mathrm{~kg}$ on a balance beam scale with participants wearing light clothes without shoes. BMI was calculated as weight $(\mathrm{kg})$ divided per squared height (meters). Body composition was evaluated by BIA (Human IM Plus II - DS Medica, Milano, Italia). Circumferences were measured with a flexible steel tape to the nearest $1 \mathrm{~mm}$; arm, flex arm, thigh, and calf circumferences were measured on the left side of the body, and waist circumference was measured at the level of the natural waist, i.e., the narrowest part of the torso. Impedance for the whole body was measured at $50 \mathrm{kHz}$ in the post-absorptive state, at an ambient temperature of $22-24{ }^{\circ} \mathrm{C}$ after voiding and after being in the supine position for $20 \mathrm{~min}$. Bioimpedance index was calculated as the ratio squared height $\left(\mathrm{m}^{2}\right) /$ resistance $(\Omega)$. FFM was calculated by Kushner's formula [21].

REE was measured by indirect calorimetry using a canopy system (V max29, Sensor Medics, Anaheim, CA, USA) at room temperature $\left(23-25^{\circ} \mathrm{C}\right)$. The instrument was checked by burning ethanol while oxygen and carbon dioxide analyzers were calibrated using nitrogen and standardized gases (mixtures of nitrogen, carbon dioxide, and oxygen). All patients were in the postabsorptive condition (12-14 h fasting), lying down on the bed, in a quiet environment. Females were in the postmenstrual phase. After a 15-min adaptation period, oxygen consumption and carbon dioxide production were determined for $45 \mathrm{~min}$. The inter-day coefficient of variation (as determined in 6 obese individuals on subsequent days) was always less than 3\%. Energy expenditure was then calculated according to the abbreviated Weir's formula, neglecting protein oxidation [22].

The hand-grip strength using the JAMAR Hydraulic Hand Dynamometer and the Short Physical Performance Battery (SPPB) were performed in order to assess physical function and mobility.

The hand-grip strength was determined three times bilaterally with the Jamar dynamometer (in the second handle position) while the patient was in the standing position with the shoulder adducted in zero degrees of rotation, the elbow flexed $90^{\circ}$ and the wrist in neutral position [23]. The results of three measurements were averaged for analysis.

The SPPB battery consists of three components of physical performance: i) chair stands, ii) standing balance, iii) gait speed. A score from 0 (poorest) to 4 (best) was assigned for each of these three components. The sum of the scores provided a composite score ranging from 0 to 12; physical performance was considered impaired when the total SPPB score was $\leq 8$ [24].

Quality of life was assessed by the administration oh the Short-Form Health Survey questionnaire (SF-36) [25].

All subjects were randomly assigned to different dietary protocols and followed for 4 months:

(1) Low-calorie diet (group A) plus placebo

(2) Low-calorie high-protein diet (1.2-1.4 g / kg body weight reference / day obtained with the addition of $15 \mathrm{~g}$ daily of protein supplement) (group B).

The characteristics of the low-calorie diet A were:

- $\quad$ daily energy intake $=$ metabolic rate (REE) $-10 \%$ according to calorimetry

- $\quad$ protein intake : 0.8-1 g / kg body weight reference / day

- carbohydrates: $60-65 \%$ of whole kcal

- $\quad$ fat: to supply the required amount of energy, with $30 \%$ saturated

- $\quad$ sodium: 5- $6 \mathrm{~g} /$ day, or less than $5 \mathrm{~g} /$ day in hypertensive subjects. The high-protein low-calorie diet B differed for protein content:

- $\quad$ energy = basal metabolic rate (REE) - $10 \%$ according to calorimetry

- $\quad$ protein intake: $1.2-1.4 \mathrm{~g} / \mathrm{kg}$ body weight reference / day with $15 \mathrm{~g}$ of protein of high biological value for each main meal (breakfast, lunch and dinner) 
Table 1. Body composition and REE in two groups of sarcopenic obese women after 4 months of treatment

\begin{tabular}{|c|c|c|c|c|c|c|}
\hline & \multicolumn{3}{|c|}{ Group A $(n=9)$} & \multicolumn{3}{|c|}{ Group B $(n=9)$} \\
\hline & baseline & $\begin{array}{l}4 \text { months } \\
(\Delta \%)\end{array}$ & $\mathrm{p}$ & baseline & $\begin{array}{l}4 \text { months } \\
(\Delta \%)\end{array}$ & $p$ \\
\hline Weight, kg & $107.6 \pm 10.2$ & $\begin{array}{l}103.5 \pm 11.9 \\
(-3.8)\end{array}$ & 0.05 & $98.9 \pm 12.7$ & $\begin{array}{l}95.0 \pm 13.3 \\
(-3.9)\end{array}$ & 0.01 \\
\hline FFM, kg & $47.7 \pm 3.34$ & $\begin{array}{l}48.0 \pm 2.83 \\
(0.6)\end{array}$ & n.s. & $47.6 \pm 2.45$ & $\begin{array}{l}48.7 \pm 2.11 \\
(2.3)\end{array}$ & 0.05 \\
\hline FAT, kg & $59.9 \pm 9.35$ & $\begin{array}{l}55.5 \pm 10.7 \\
(-7.3)\end{array}$ & 0.03 & $51.3 \pm 10.9$ & $\begin{array}{l}46.3 \pm 12.3 \\
(-9.7)\end{array}$ & 0.01 \\
\hline FAT, $\%$ & $55.4 \pm 4.46$ & $\begin{array}{l}53.2 \pm 4.8 \\
(-4.0)\end{array}$ & 0.05 & $51.4 \pm 4.52$ & $\begin{array}{l}48.0 \pm 6.1 \\
(-6.6)\end{array}$ & 0.05 \\
\hline AF, degree & $5.6 \pm 0.6$ & $\begin{array}{l}5.6 \pm 0.5 \\
(0)\end{array}$ & n.s. & $6 \pm 0.5$ & $\begin{array}{l}5.8 \pm 0.5 \\
(-3.3)\end{array}$ & n.s. \\
\hline REE, kcal/day & $1751 \pm 175$ & $\begin{array}{l}1,708 \pm 234 \\
(-2.5)\end{array}$ & n.s & $1,678 \pm 221$ & $\begin{array}{l}1613 \pm 246 \\
(-3.9)\end{array}$ & n.s. \\
\hline QR & $0.85 \pm 0.09$ & $\begin{array}{l}0.80 \pm 0.05 \\
(-5.9)\end{array}$ & n.s. & $0.86 \pm 0.08$ & $\begin{array}{l}0.82 \pm 0.02 \\
(-4.7)\end{array}$ & n.s. \\
\hline REE/FFM, kcal/kg & $36.7 \pm 1.99$ & $\begin{array}{l}36.5 \pm 3.04 \\
(-0.5)\end{array}$ & n.s & $35.2 \pm 3.64$ & $\begin{array}{l}34.4 \pm 4.36 \\
(-2.3)\end{array}$ & n.s. \\
\hline
\end{tabular}

$\Delta \%=$ Percent change versus baseline.

Group A: low-calorie diet.

Group B: low-calorie high-protein diet (1.2-1.4 g / kg body weight reference / day obtained with the addition of $15 \mathrm{~g}$ daily of protein supplement).

- $\quad$ essential amino acids < branched-chain amino acids < leucine equal to $15 \mathrm{~g} /$ day by administration of supplement;

- $\quad$ carbohydrate: $60-65 \%$ of kcal complex

- $\quad$ fat: to satisfy the required amount of energy; $30 \%$ saturated

- $\quad$ report non-protein $\mathrm{kcal} / \mathrm{g}$ nitrogen $=100 / 1$

- $\quad$ sodium: less than $5 \mathrm{~g} /$ day in hypertensive subjects.

Adherence to diets was evaluated by a 7-day dietary record at baseline and at week 4, 8, 12, 16, and was reinforced by the dietitians through counseling and phone calls every 2 weeks.

All data were computerized and analyzed with a dedicated software (SPSS for Windows version 14 (IBM Corp, Armonk, NY, USA)). All results are expressed as mean \pm SD. Student's t-test for unpaired data was used to evaluate the differences between groups. Two-way analysis of variance (ANOVA) was performed to compare data between different groups. Wilcoxon and Mann Whitney test were performed for non-parametric data.

Differences were considered statistically significant for $\mathrm{p}$ values $<0.05$.

\section{Results}

At entry, anthropometric measurements and body composition of the two groups showed no significant differences for age (group A vs. B: $58 \pm 10$ vs. $53 \pm 8.9$ years), weight (A vs. B: $108 \pm 10.2$ vs. $99 \pm 12.7 \mathrm{~kg}$ ), BMI (A vs. B: $43.6 \pm 4.3$ vs. $39.2 \pm 5.4 \mathrm{~kg} / \mathrm{m}^{2}$ ), FFM (A vs. B: 47.7 \pm 3.34 vs. $47.6 \pm 2.45 \mathrm{~kg}$ ), whereas fat mass (A vs. B: $59.9 \pm 9.35$ vs. $51.3 \pm 10.9 \mathrm{~kg}$ ) was significantly lower in group B.

Changes in weight, body composition, and resting energy expenditure of 18 women divided into two diet groups after the 4 months of treatment are reported in table 1. 
Sammarco et al.: Evaluation of Hypocaloric Diet With Protein Supplementation in Middle-Aged Sarcopenic Obese Women: A Pilot Study

Table 2. Body circumferences after 4 months of treatment in two groups of sarcopenic obese women

\begin{tabular}{|c|c|c|c|c|c|c|}
\hline & \multicolumn{3}{|c|}{ Group A $(n=9)$} & \multicolumn{3}{|c|}{ Group B $(n=9)$} \\
\hline & baseline & $\begin{array}{l}4 \text { months } \\
(\Delta \%)\end{array}$ & $\mathrm{p}$ & baseline & $\begin{array}{l}4 \text { months } \\
(\Delta \%)\end{array}$ & $\mathrm{p}$ \\
\hline Arm, cm & 39.7 & $38.3(-3.5)$ & n.s. & 36.9 & $36.1(-2.2)$ & n.s. \\
\hline Flex arm, cm & 40.3 & $38.9(-3.5$ & n.s. & 37.4 & $36.6(-2.1)$ & n.s. \\
\hline Calf, cm & 41.0 & $39.9(-2.7)$ & n.s. & 39.7 & $39.4(-0.8)$ & n.s. \\
\hline Thigh, cm & 56.7 & $56.1(-1.1)$ & n.s. & 56.1 & $55.4(-1.2)$ & n.s. \\
\hline Waist, cm & 116.3 & $111.8(-3.9)$ & n.s. & 102.7 & $101.7(-0.1)$ & n.s. \\
\hline
\end{tabular}

$\Delta \%=$ Percent change versus baseline. Group A: low-calorie diet. Group B: low-calorie high-protein diet (1.2-1.4 g / kg body weight reference / day obtained with the addition of $15 \mathrm{~g}$ daily of protein supplement).

Table 3. Functional parameters (hand grip and SPPB) after 4 months of treatment

\begin{tabular}{|c|c|c|c|c|c|c|}
\hline & \multicolumn{3}{|c|}{ Group A $(n=9)$} & \multicolumn{3}{|c|}{ Group B $(n=9)$} \\
\hline & baseline & $\begin{array}{l}4 \text { months } \\
(\Delta \%)\end{array}$ & $\mathrm{p}$ & baseline & $\begin{array}{l}4 \text { months } \\
(\Delta \%)\end{array}$ & $\mathrm{p}$ \\
\hline $\mathrm{HG}, \mathrm{kg}$ & $16.4 \pm 3.89$ & $16.4 \pm 3.33(0)$ & n.s. & $16.6 \pm 3.74$ & $18.2 \pm 3.56(9.6)$ & 0.01 \\
\hline SPPB & $7.7 \pm 2.6$ & $7.2 \pm 2.9(-6.4)$ & n.s. & $10.1 \pm 1.54$ & $10 \pm 1.45(-1)$ & n.s. \\
\hline
\end{tabular}

$\Delta \%=$ Percent change vs. baseline; $\mathrm{HG}=$ hand grip; $\mathrm{SPPB}=$ short physical performance battery.

Group A: low-calorie diet.

Group B: low-calorie high-protein diet (1.2-1.4 g / kg body weight reference / day obtained with the addition of $15 \mathrm{~g}$ daily of protein supplement).

Weight and fat mass significantly decreased $(\mathrm{p}<0.05)$ in both groups after 4 months of dietary treatment.

Women in group A showed a greater reduction of lean body mass compared to protein enriched diet (group $A=-1.3 \mathrm{~kg}$, group $B=-0.5 \mathrm{~kg} ; \mathrm{p}<0.05$ ). Phase angle derived from BIA did not change significantly in both groups (group $A=$ unchanged, group $B=-0.2^{\circ}$; not significant).

REE did not change significantly in both experimental groups $(A=-43 \mathrm{kcal} /$ day, group $\mathrm{B}=-65 \mathrm{kcal} /$ day). The results are similar after correction for FFM (group $\mathrm{A}=+1.0 \mathrm{kcal} / \mathrm{kg}$, group $\mathrm{B}=+0.4 \mathrm{kcal} / \mathrm{kg}$ ). Respiratory quotient (RQ) is reported in table 1 .

Table 2 shows data on circumferences of the arm, flexed arm, calf, thigh, and waist that did not change significantly in the two groups after 4 months.

Table 3 shows the results of the functional tests. Muscle strength measured by dynamometry improved significantly in the group with protein supplementation (group $A=$ unchanged, group $B=+1.6 \mathrm{~kg}$ ). The score of SPPB test did not change significantly in both groups (group $A=-0.5 ; B=-0.01$ ). The two groups did not differ after 4 months.

Table 4 shows the results of the SF-36 test. The only significant change after 4 months is the score of general health in the group with high-protein diet (baseline vs. 4 months : 54 vs. $63 ; p=0.028$ ); all other categories (physical activity, physical role limitations, physical pain; vitality, social activities; emotional role limitations, mental health) did not change significantly in both groups. There were no statistically significant differences between groups after 4 months of treatment. 
Table 4. Score of SF-36 test

\begin{tabular}{|c|c|c|c|c|c|c|}
\hline & \multicolumn{3}{|c|}{ Group A $(n=9)$} & \multicolumn{3}{|c|}{ Group B $(n=9)$} \\
\hline & baseline & 4 months & $\mathrm{p}$ & baseline & 4 months & $\mathrm{p}$ \\
\hline Physical activity & 65 & 61 & n.s. & 75 & 86 & n.s. \\
\hline Physical role limitations & 50 & 58 & n.s. & 84 & 87 & n.s. \\
\hline Physical pain & 38 & 61 & n.s & 57 & 68 & n.s \\
\hline General health & 56 & 51 & n.s. & 54 & 63 & 0.03 \\
\hline Vitality & 41 & 45 & n.s. & 58 & 58 & n.s. \\
\hline Social activities & 58 & 58 & n.s. & 76 & 81 & n.s. \\
\hline Emotional role limitations & 55 & 44 & n.s. & 66 & 66 & n.s. \\
\hline Mental health & 45 & 49 & n.s. & 63 & 60 & n.s. \\
\hline
\end{tabular}

$\Delta \%=$ Percent change versus baseline.

Group A: low-calorie diet.

Group B: low-calorie high-protein diet (1.2-1.4 g / kg body weight reference / day obtained with the addition of $15 \mathrm{~g}$ daily of protein supplement).

\section{Discussion}

Management of sarcopenic obesity is becoming increasingly important since the elderly population, and also the prevalence of obesity in this group, is expanding in the western world [26].

There are only few studies in the literature, reporting nutritional intervention or physical rehabilitation in adult patients with sarcopenic obesity. First, there are many doubts about the adequacy of the recommended daily allowance (RDA) of dietary protein in older adults $(0.8-1 \mathrm{~g} / \mathrm{kg}$ body weight reference / day), although the protein intake is needed to maintain the nitrogen balance in the short term [27], but not for the maintenance of lean body mass. Current recommendations for protein requirement [27] were determined according to studies performed in healthy individuals, and, to date, they may not be thoroughly adequate when considering relevant alterations in body compartments such as obesity in adult life or in a complex condition such as sarcopenic obesity.

Although the RDA of protein is adequate to maintain weight, low-protein hypocaloric diets may lead to weight loss and sarcopenia, particularly inducing weight cycling when repeated. In the Health ABC Study Cohort study [28] the highest intake of protein has been associated with a lower loss of lean body mass in participants who have lost weight in the 3 -year of follow-up. Participants who had kept the weight stable had lost less lean body mass than those who had lost weight. Finally, higher intake of protein was associated with increased lean body mass in individuals who had gained weight in the 3-year of follow-up.

However, further research is required to confirm that intake of proteins higher than usually recommended is able to counteract the loss of lean body mass in sarcopenic obese subjects on low-calorie diets.

In our study, the protein-enriched diet (1.2-1.4 g / kg body weight reference / day with $15 \mathrm{~g}$ of protein of high biological value for main meals) improved both body composition and muscle strength in sarcopenic obese women. Patients with high-protein diet showed an increased muscle strength (score $+1.6 \mathrm{~kg}$ ) after 4 months of treatment. This result has, in our view, important clinical implications. Indeed, the assessment of muscle strength is a noninvasive and low-cost method, and muscle strength requires special attention since several studies demonstrate that it could be a death predictor in the elderly [29]. On the other hand, 
the SPPB score was unchanged in the two groups. In our view this could be related to the relatively short term of observation.

One of the more significant findings emerging from our study is that sarcopenia was found in middle-aged obese subjects. Papers reporting similar results are rather rare [30]. In line with the hypothesis that obesity produces low-grade inflammation and hormonal changes affecting muscle function and metabolism, even young people could have similar changes and meet the criteria for the diagnosis of sarcopenic obesity. Moreover, pronounced and prolonged inactivity together with frequently repeated unbalanced diets leading to rapid weight loss may deeply affect lean body mass.

Another limitation of our study is the small sample size. Therefore, further studies are required in a larger population of obese women of middle age in order to determine the association between dietary protein intake and changes in lean body mass, which could have important implications for developing strategies for weight loss in these subjects and for the prevention of sarcopenia, one of the possible causes of physical disability associated with aging.

In conclusion, we are aware that a definition of sarcopenia requires a thorough evaluation considering body composition, muscle strength, and physical performance, and other studies should be encouraged to confirm the effect of dietary protein enrichment in the treatment of sarcopenic obesity with a hypocaloric diet, particularly in younger age groups.

\section{Acknowledgments}

This study was supported by MIUR PRIN 2009.

\section{Author Contributions}

F.P. and L.M.D. designed research; R.S.,M.N. and M.D.G: conducted research; M.M., E.P., and F.C. analyzed and discussed all data; R.S., F.P, and M.M. wrote the paper. M.M. and F.P. had primary responsibility for final content. All authors read and approved the final manuscript.

\section{Disclosure Statement}

None of the authors had any conflict of interest.

\section{References}

1 Rosenberg I: Summary comments: epidemiological and methodological problems in determining nutritional status of older persons. Am J Clin Nutr 1989;50:1231-1233.

2 Baumgartner RN, Koehler KM, Gallagher D, Romero L, Heymsfield SB, Ross RR, et al: Epidemiology of sarcopenia among the elderly in New Mexico. Am J Epidemiol 1998;147:755-763.

3 Janssen I, Baumgartner R, Ross R, et al: Skeletal muscle cutpoints associated with elevated physical disability risk in older men and women. Am J Epidemiol 2004;159:413-421.

4 Cruz-Jentoft AJ, Baeyens JP, Bauer JM, Boirie Y, Cederholm T, Landi F, et al: Sarcopenia: European consensus on definition and diagnosis: report of the European Working Group on Sarcopenia in Older People. Age Ageing 2010;39:412-423.

5 Donini LM, Poggiogalle E, Migliaccio S, Pinto A, Lubrano C, Leanzi A: Sarcopenic obesity: correlation with clinical, functional, and psychological status in a rehabilitation setting. Food Nutr Sci 2014;5:2020-2031.

6 Heber D, Ingles S, Ashley JM, Maxwell MH, Lyons RF, Elashoff RM: Clinical detection of sarcopenic obesity by bioelectrical impedance analysis. Am J Clin Nutr 1996;64(3 suppl):S472-S477.

7 Donini LM, Poggiogalle E, Migliaccio S, Aversa A, Pinto A: Body composition in sarcopenic obesity: systematic review of the literature. Mediterr J Nutr Metab 2013;6:191-198. 
8 Zamboni M, Mazzali G, Fantin F, Rossi A, Di Francesco V: Sarcopenic obesity: a new category of obesity in the elderly. Nutr Metab Cardiovasc Dis 2008;18,388-395.

9 Bogdanis GC: Effects of physical activity and inactivity on muscle fatigue. Front Physiol 2012;3:142.

10 Kewalramani G, Bilan PJ, Klip A: Muscle insulin resistance: assault by lipids, cytokines and local macrophages. Curr Opin Clin Nutr Metab Care 2010;13:382-390.

11 Lee JS, Visser M, Tylavsky FA, Kritchevsky SB, Schwartz AV, Sahyoun N, Harris TB, Newman AB: Health ABC study: weight loss and regain and effects on body composition: the health, aging, and body composition study. J Gerontol A Biol Sci Med Sci 2010;65:78-83.

12 Prado CM, Wells JC, Smith SR, Stephan BC, Siervo M: Sarcopenic obesity: a critical appraisal of the current evidence. Clin Nutr 2012;31:583-601.

13 De Rosa E, Santarpia L, Marra M, Sammarco R, Amato V, Onufrio M, De Simone G, Contaldo F, Pasanisi F: Preliminary evaluation of sarcopenia in obese patients in Southern-Italy. Nutrition 2015;31:79-83.

14 Sammarco R, Marra M, Montagnese C, De Rosa E, Onufrio M, Amato V, Santarpia L, De Caprio C, Contaldo F, Pasanisi F: Screening for sarcopenia in obesity. J Phys ConfSer 2013;434:012044. http://iopscience.iop.org/ article/10.1088/1742-6596/434/1/012044 (last accessed April 28, 2017).

15 Poggiogalle E, Migliaccio S, Lenzi A, Donini LM: Treatment of body composition changes in obese and overweight older adults: insight into the phenotype of sarcopenic obesity. Endocrine 2014;47:699-716.

16 Merra G, Miranda R, Barrucco S, Gualtieri P, Mazza M, Moriconi E, Marchetti M, Chang TF, De Lorenzo A, Di Renzo L: Very-low-calorie ketogenic diet with aminoacid supplement versus very low restricted-calorie diet for preserving muscle mass during weight loss: a pilot double-blind study. Eur Rev Med Pharmacol Sci 2016; 20:2613-2621.

17 Deurenberg P, Yap M, van Staveren WA: Body mass index and percent body fat: a meta-analysis among different ethnic groups. Int J Obes 1998;22;1164-1171.

18 World Health Organization: Report of a WHO Expert Committee Physical Status: The Use and Interpretation of Anthropometry. WHO Technical Report Series 854, Geneva, WHO, 1995.

19 Joosen AM, Bakker AH, Westerterp KR: Metabolic efficiency and energy expenditure during short- term overfeeding. Physiol Behav 2005;85:593-597.

20 Norgan NG, Durnin JV: The Effect of 6 weeks of overfeeding on the body weight, body composition, and energy metabolism of young men. Am J Clin Nutr 1980;33:978-988.

21 Kushner RF, Schoeller DA, Fjeld CR, Danford L: Is the impedance index (ht2/R) significant in predicting total body water? Am J Clin Nutr 1992:56:835-839.

22 Weir JB: New methods for calculating metabolic rate with special reference to protein metabolism. J Physiol 1949;109:1-9.

23 Fess E: Grip strength. Clinical Assessment Recommendations, 2nd ed. Chicago, American Society of Hand Therapists, 1992, pp 41-45.

24 Guralnik JM, Simonsick EM, Ferrucci L, et al: A short physical performance battery assessing lower extremity function: association with self-reported disability and prediction of mortality and nursing home admission. J Gerontol 1994;49:M85-94.

25 Hays RD, Sherbourne CD, Mazel RM: The RAND 36-Item Health Survey 1.0. Health Economics 1993;2:217227.

26 Ogden CL, Carroll MD, Curtin LR, McDowell MA, Tabak CJ, Flegal KM: Prevalence of overweight and obesity in the United States, 1999-2004. JAMA 2006;295:1549-1555.

27 World Health Organization: Protein and Amino Acid Requirements in Human Nutrition: report of a joint FAO/ WHO/ UNU expert consultation. WHO Technical Report Series 935. Geneva, WHO, 2011.

28 Houston DK, Nicklas BJ, Ding J, Harris TB, Tylavsky FA, Newman AB, Lee JS, Sahyoun NR, Visser M, Kritchevsky SB; Health ABC Study: Dietary protein intake is associated with lean mass change in older, communitydwelling adults: the Health, Aging, and Body Composition (Health ABC) Study. Am J Clin Nutr 2008;87:150155.

29 Norman K, Stobaus N, Gonzales MC, Schulze JD, Pirlich M: Handgrip strength: outcome predictor and marker of nutritional status. Clin Nutr 2008;30:135-142.

30 Gonzalez-Correa $\mathrm{CH}$, Caicedo-Eraso JC, Villada-Gomez JS: Bioelectrical impedance analysis for sarcopenic obesity diagnosis in young female subjects. J Phys Conf Ser 2013;434:012061 http://iopscience.iop.org/ article/10.1088/1742-6596/434/1/012061/meta (last accessed April 28, 2017). 